\title{
Air pollution in European countries and life expectancy—modelling with the use of neural network
}

\author{
Alicja Kolasa-Więcek ${ }^{1}$ (D) $\cdot$ Dariusz Suszanowicz ${ }^{1}$ (D)
}

Received: 12 June 2019 / Accepted: 5 September 2019/Published online: 30 October 2019

(C) The Author(s) 2019

\begin{abstract}
The present paper discusses a novel methodology based on neural network to determine air pollutants' correlation with life expectancy in European countries. The models were developed using historical data from the period 1992-2016, for a set of 20 European countries. The subject of the analysis included the input variables of the following air pollutants: sulphur oxides, nitrogen oxides, carbon monoxide, particulate matters, polycyclic aromatic hydrocarbons and non-methane volatile organic compounds. Our main findings indicate that all the variables significantly affect life expectancy. Sensitivity of constructed neural networks to pollutants proved to be particularly important in the case of changes in the value of particulate matters, sulphur oxides and non-methane volatile organic compounds. The most frequent association was found for fine particle. Modelled courses of changes in the variable under study coincide with the actual data, which confirms that the proposed models generalize acquired knowledge well.
\end{abstract}

Keywords Air pollution $\cdot$ Life expectancy $\cdot$ Public health $\cdot$ Artificial neural network $\cdot$ Modelling $\cdot$ Multi-layer perceptron

\section{Introduction}

Air pollution is a very important environmental factor. In order to take effective actions aimed at reducing the impact of air pollution on people, ecosystems and climate, it is necessary to understand the causes of its formation, transportation and transformation in the atmosphere (European Environment Agency). Pollutants such as particulate matters (PM10, PM2.5), sulphur dioxide $\left(\mathrm{SO}_{2}\right)$, volatile organic compound (VOC), carbon monoxide $(\mathrm{CO})$ and nitrogen oxides $\left(\mathrm{NO}_{\mathrm{x}}\right)$ are mainly released from gasoline used in diesel-run vehicles, industrial plants and heating processes due to anthropogenic activities (Ashraf et al. 2019). For individual people, the possibility to avoid exposure to air pollutants is very limited; therefore, actions must be taken by the national, regional and

Alicja Kolasa-Więcek

akolasa@uni.opole.pl

Dariusz Suszanowicz

d.suszanowicz@uni.opole.pl

1 Faculty of Natural Sciences and Technology, Institute of Technical Sciences, University of Opole, 7-9 Dmowskiego Str, 45-365 Opole, Poland international public authorities. To reduce the impact of air pollution on human health, it is necessary to develop longterm policies involving multiple sectors, such as transport, housing, energy production and industry (World Health Organization WHO). Air pollution is responsible for many diseases affecting the heart, skin, eyes and other organs, and exposure to smog is the cause of various inflammatory responses. Therefore, it is of vital importance to use ambient air quality measurements in order to get an insight into the air quality of a given region (Cacciotolo et al. 2017).

Even short-term exposure to air pollution affects health. In studies carried out in Europe and worldwide, a link has been documented between the level of air pollution with particulates and gases and the state of health, measured in the form of deaths and/or hospitalizations (Alessandrini et al. 2016; Fann et al. 2019; Li et al. 2016; Samoli et al. 2013; World Health Organization).

Emissions of many air pollutants in Europe have decreased significantly over the last decades, which has contributed to the improvement of air quality (European Economic Area EEA). Much progress has been made in tackling air pollutants such as $\mathrm{SO}_{2}, \mathrm{CO}$, lead $(\mathrm{Pb})$, and benzene $\left(\mathrm{C}_{6} \mathrm{H}_{6}\right)$. On the other hand, road transport, industry, power plants, households and agricultural activities continue to emit significant amounts of air pollutants (Guerreiro et al. 2014). Consequently, concentrations of air pollutants are still too high and problems with air quality 
persist. A significant part of the European population lives in areas where air-quality standards are constantly exceeded (Fig. 1).

Although targeted policies and technological advancement have brought about positive changes in European air quality over the last decade, between 2014 and 2016, the concentration of certain air pollutants in many European cities was still above EU limit or target values. In relation to the WHO guidelines established for the protection of human health, the numbers of people exposed were even higher (Fig. 1, EEA).

Air pollution continues to have a significant impact on the health of the European population, particularly in urban areas. Several sectors failed to limit emissions significantly enough to meet air-quality standards (European Environment Agency EEnA). Emission levels of certain pollutants have even increased. For example, the levels of $\mathrm{NO}_{\mathrm{x}}$ emissions from road transport in many urban areas still exceed air-quality standards. Coal and biomass combustion in households and from commercial and institutional building is still the main culprit of PM and benzo(a)pyrene (BaP) emissions in the $\mathrm{EU}$, and attempts at their reduction have brought no success (EEnA). Concentrations of PM continued to exceed the EU limit and target values in large parts of Europe in 2014 (EEnA). Several economies with particularly high levels of atmospheric emissions stand out among European countries (Fig. 2).

To fully meet EU air-quality standards set for the protection of human health and natural environment, it is necessary to undertake efforts aimed at limiting emissions of air pollutants. All countries should follow European Community guidelines concerning air pollution emissions. EU countries differ in many respects (population, area of the country, topographic diversity, degree of industrialization, degree of conventional energy sources usage, condition of roads, condition of vehicle fleet, etc.). This diversity accounts for differences in the sources and quantities of emitted pollutants.

An estimated 4.5 billion people are currently exposed to PM levels at least twice the concentration that the WHO considers safe (Ebenstein et al. 2017). Among the many health

\section{a}

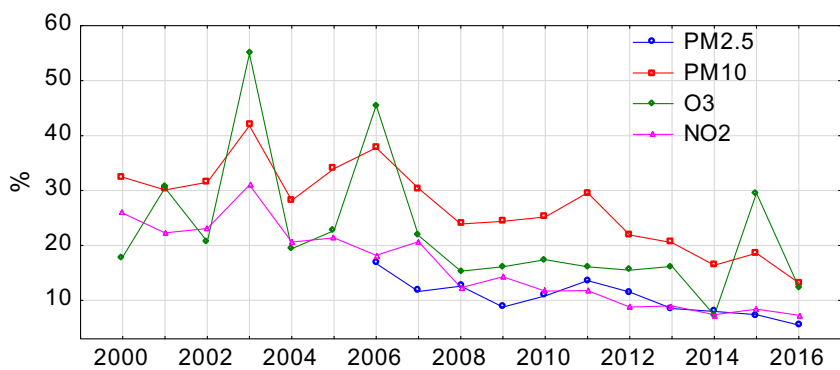

Fig. 1 Urban population in percentage exposed to air pollutant concentrations above selected limit and target values according to a UE air-quality standards; ${ }^{1} \mathbf{b}$ WHO air quality guideline. ${ }^{1}$ Percentage of population exposed to annual PM2.5 concentrations above $25 \mu \mathrm{g} / \mathrm{m}^{3}$; percentage of population exposed to daily PM10 concentrations exceeding 50 problems which can be caused by air pollution are respiratory and cardiovascular diseases, lung cancer and even premature death (Park and Kwan 2017).

The impact of air pollution on LE is being increasingly addressed in scientific research. However, despite the welldocumented literature on the association between air pollution and health problems, studies regarding the effects on LE are still globally scarce (Aboubacar et al. 2018; De Keijzer et al. 2017; Wang et al. 2013; Jonker et al. 2014). Fann et al. 2017 estimated that the US population will experience an increase in LE due to reductions in annual mean PM2.5 concentrations from 1980 to 2010. De Keijzer et al. (2017) presented that air pollution concentrations were associated with important reductions in LE. Studies conducted by Dziubanek et al. (2017) confirmed the presence of significant correlations between the size of the chronic exposure of the inhabitants of the cities of the Silesia Province in Poland to PM10 and BaP and their LE, excluding external causes of death. Air quality might have contributed substantially to the LE in China (Wang et al. 2013). LE increased from 2003 to 2009, but slightly decreased in 2010, which was related to the increased PM10 level in 2010. Approaches of Aboubacar et al. (2018) provide similar results indicating that household PM2.5 is significantly and negatively associated with higher aggregate LE in the longrun, and to a greater degree for female's. Also, among the control variables, PM2.5 from the transport sector has a greater influence on male's LE. Etchie et al. (2018) estimated the share of the deaths, DALYs (disability adjusted-life years), economic cost and loss in LE attributable to population exposure to ambient PM2.5 pollution at the local, sub-national level in Nigeria in 2000 and 2015. Hill et al. (2019) estimated models with interaction terms to formally assess whether the association between fine particulate matter and LE varies by level of state income inequality.

Air pollution models represent an important tool in environmental and epidemiological science (Liu et al. 2019; Mehdipour et al. 2018). Little attention is given to applying the modelling technique to investigate not only share of PM

\section{b}

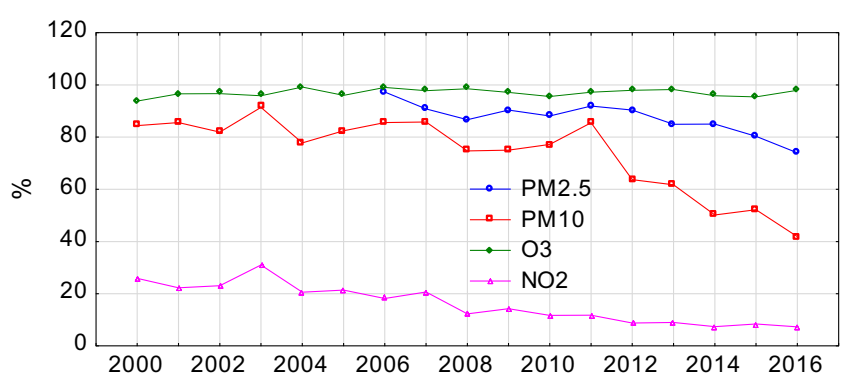

$\mu \mathrm{g} / \mathrm{m}^{3}$ for more than 35 days a year; percentage of population exposed to maximum daily 8-h mean $\mathrm{O}_{3}$ concentrations exceeding $120 \mu \mathrm{g} / \mathrm{m}^{3}$ for more than 25 days a year; percentage of population exposed to annual $\mathrm{NO}_{2}$ concentrations above $40 \mu \mathrm{g} / \mathrm{m}^{3}$ 


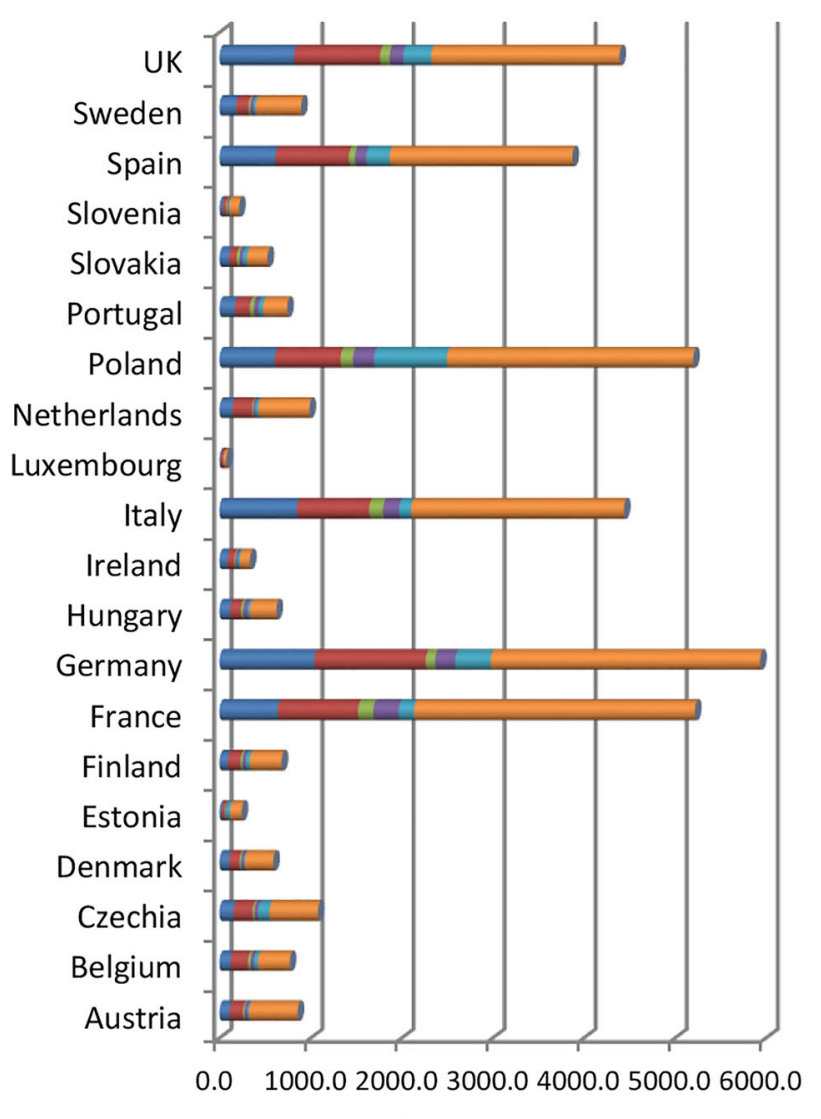

Thous. tonnes

$\square$ NMVOCs $\square$ NOx $\square$ PM2.5 $\square$ PM10 $\square$ SOx $\square$ CO $\square$ PAHs

Fig. 2 Air pollution in European countries in 2015

but also other air pollutants in the impact on LE. The goal of this study was to develop a new approach to modelling of life expectancy (LE) depending on air pollutants (sulphur oxides $\mathrm{SO}_{\mathrm{x}}, \mathrm{NO}_{\mathrm{x}}, \mathrm{CO}, \mathrm{PM} 2.5$ and PM10, polycyclic aromatic hydrocarbons PAHs and non-methane volatile organic compounds NMVOCs) using artificial neural networks (ANN) (multi-layer perceptron MLP). Research has been undertaken to determine which air pollutants are statistically highly significant and correlated with the output variable (LE) in particular countries. Evaluating the potential impact of air quality improvement on public health and LE is very important for providing continued support to mitigate air pollution in many European countries. The presented ANN model can be used not only for LE forecasting but also for simulating various scenarios of LE by changing the values of the input variables.

\section{Methods and materials}

\section{Methodology}

The present paper discusses a novel methodology based on neural network to determine air pollutants' correlation with $\mathrm{LE}$ at the national level in European countries. The models were developed using historical data from the period 1992-2016. The dataset for this analysis is based on several sources (Eurostat, OECD, European Union emission inventory report 1990-2016) for a set of 20 European countries. Study area is presented in Fig. 3.

The impact of air pollution on LE is often modelled with the use of regression analysis (Dziubanek et al. 2017; Pope et al. 2009; Pope et al. 2015; de Keijzer et al. 2017). However, the regression approach can face serious difficulties when the independent variables are correlated with each other. Multicollinearity, or high correlation between the independent variables in a regression equation, can make it difficult to correctly identify the most important contributors to a physical process (Abdul-Wahab et al.2005). Moreover, as shown in Fig. 4, not all independent variables show purely linear correlations with the dependent variable. For these reasons, it was decided to carry out tests based on ANN.

Figure 5 presents a two-dimensional scatterplot showing the dependence of LE on individual pollutants. Some independent variables show a simple linear relationship with LE, while others, despite high Pearson correlation coefficient, are better presented in the form of logarithmic functions. The graphs indicate negative correlations.

Data source for neural network training was a set of $70 \%$ of data from the period of 25 years. LE modelling was performed using an MLP and Broyden-Fletcher-Goldfarb-Shanno (BFGS) algorithm of learning. The parameters of the network, i.e. weight values and threshold values of neurons, were selected

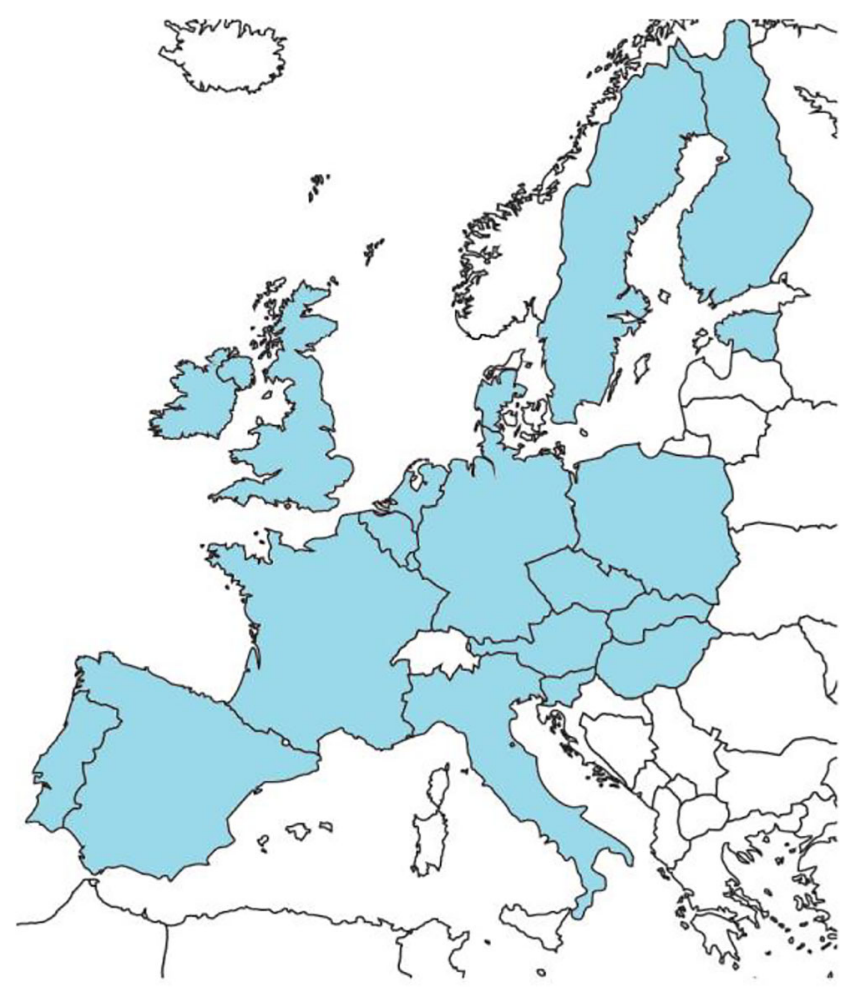

Fig. 3 Countries included in the study 
Fig. 4 MLP neural network architecture

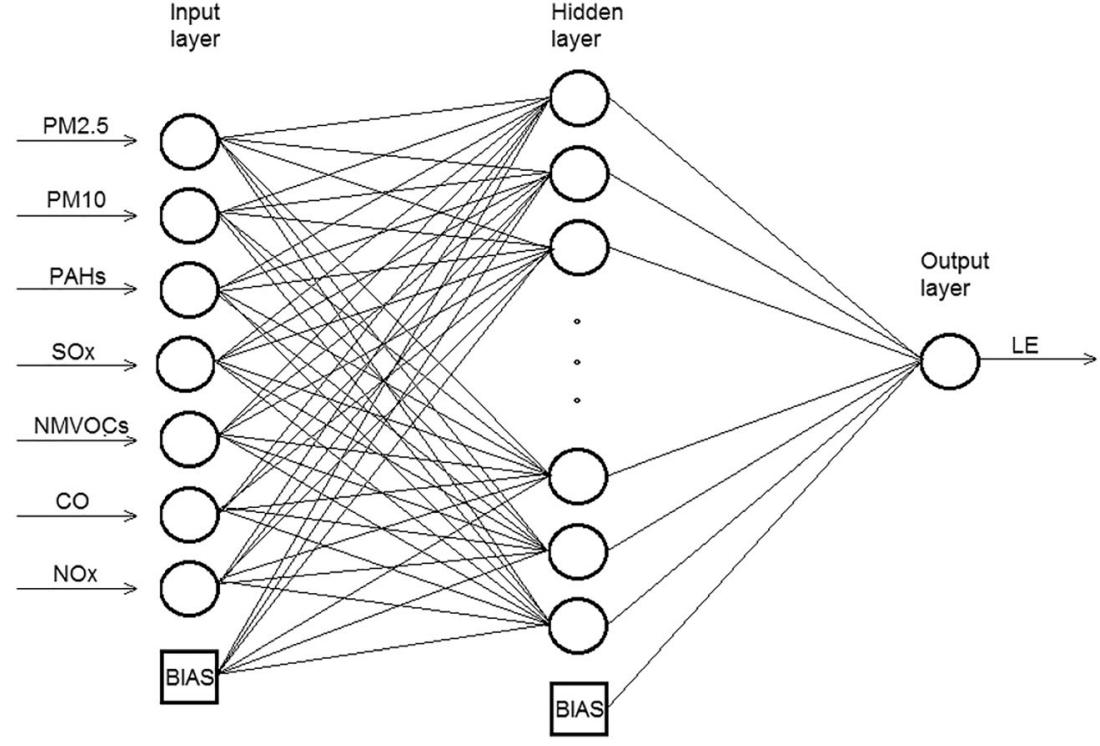

in a manner allowing for the minimisation of error function of the network. To achieve this, a special learning algorithm was applied, which enabled automatic modification of the mentioned value, based on input data and respective appropriate solutions. The training of created network model was performed by the backpropagation method, which is the most commonly used and one of the most effective learning algorithms for multilayer neural network. Its essence is based on minimising the sum of squares of network learning errors. Errors occurring at the output of the network are propagated in the opposite direction than that of signals passing through the network, i.e. from the output layer to the input layer. An automatic ANN designer simultaneously searches for multiple types of networks. Each of the analysed countries is divided into three subsets: $70 \%$ train, $15 \%$ validate, $15 \%$ test. A series of tests of the network types were carried out using the Automatic Network Designer. Sensitivity of the neural network to particular pollutants was determined in relation to $\mathrm{LE}$ by sensitivity analysis (SA). The Statistica Neural Networks module implemented in Statistica 12.5 was used to generate neural models.

\section{Multi-layer perceptron}

The structure of basic MLP model is composed of three layers: the input layer where the input data are received, the hidden layer where the objects are processed and the output layer where the forecasted results are presented.

In order to choose the most precise structure of MLP model, the method of trial and error is applied. The model's final architecture depends on the hidden layer and the values of neuron. The inputs to the $i$ th layer $\left(x_{1}\right.$ to $\left.x_{j}\right)$ multiplied by their weights $\left(w_{i 1}\right.$ to $\left.w_{i j}\right)$ are summed up. The net input value $\left(\mathrm{Net}_{i}\right)$ is determined by adding the threshold $\left(b_{i}\right)$ to the input. The received net input value is always greater than zero.
$\operatorname{Net}_{i}=b_{i}+\sum_{j=1}^{n} w_{i j} x_{j}$

Weights, which represent how strong a neuron connection is, are adjusted in the process of learning. In the next step, inputs and outputs received by the member function are transferred to the next layer. In order to introduce nonlinearity in the model, sigmoid functions can be applied.

$f\left(\mathrm{Net}_{i}\right)=\frac{1}{1+e^{\mathrm{Net}_{i}}}$

The ANN architecture used in this study is presented in Fig. 4.

Several dozens of network neurons with different numbers of neurons in the hidden layer were tested for each country. The selection criterion was the minimum error of mean square error (MSE) value for the data from the validation set.

\section{BFGS algorithm of learning}

For the purpose of the study, the BFGS algorithm of learning was chosen. Consider the following problem:

$\min _{x \in R^{n}} f(x)$

where $f: R^{n} \rightarrow R$ is twice continuously differentiable function.

The methods which are most often applied in order to solve the problem of unconstrained minimisation are the quasi-Newton methods (Broyden 1965). They are based on the iterative formula

$x_{k+1}=x_{k}+\lambda_{k} p_{k}$

where $\lambda_{k}>0$ is the step length that is updated by line search and backtracking procedure and $p_{k}-B_{k}^{-1} \nabla f\left(x_{k}\right)$ is the quasi- 
a

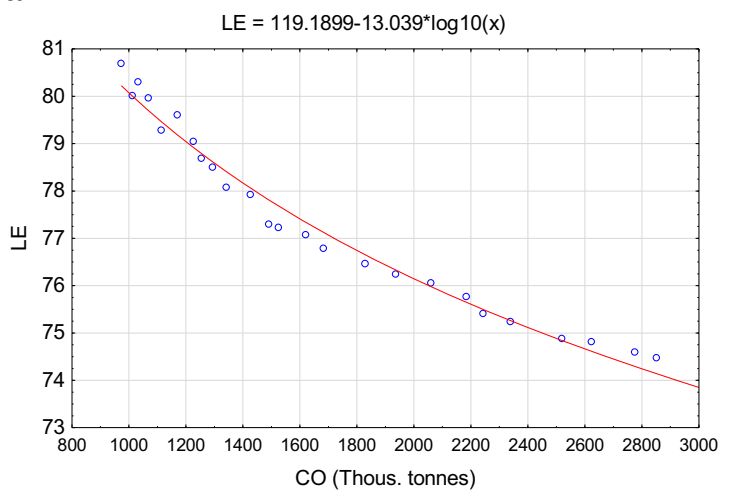

c

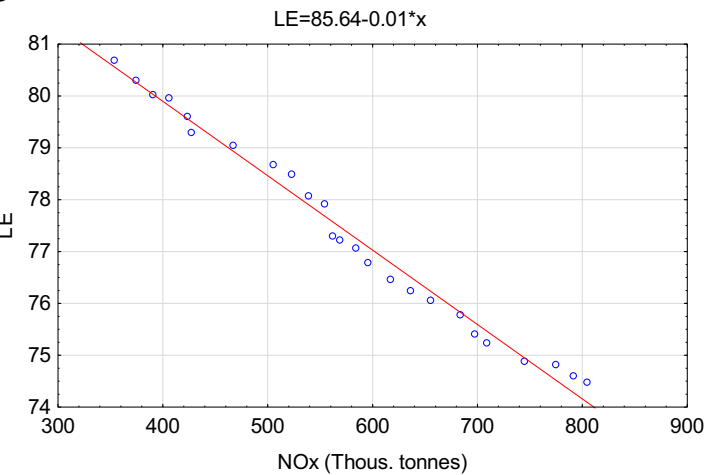

e

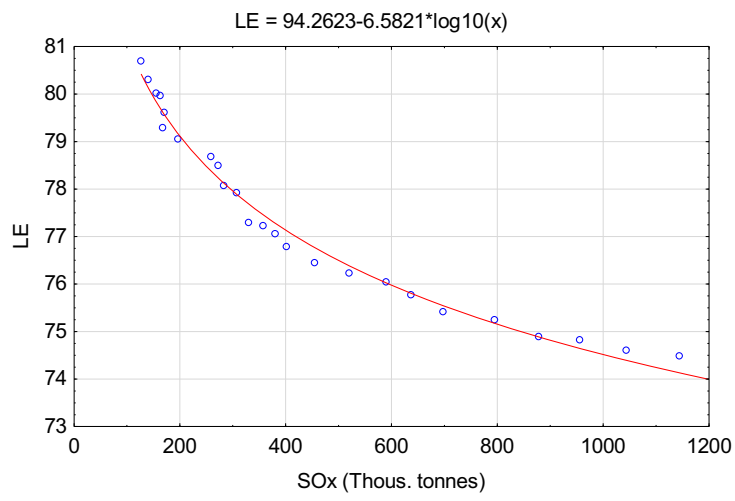

g

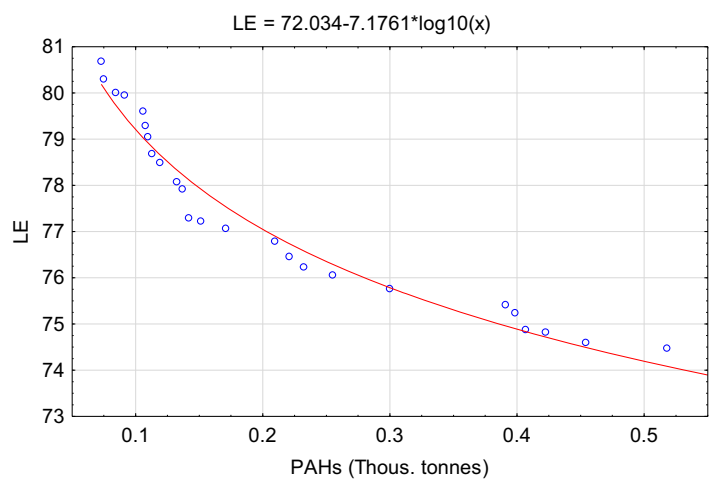

b

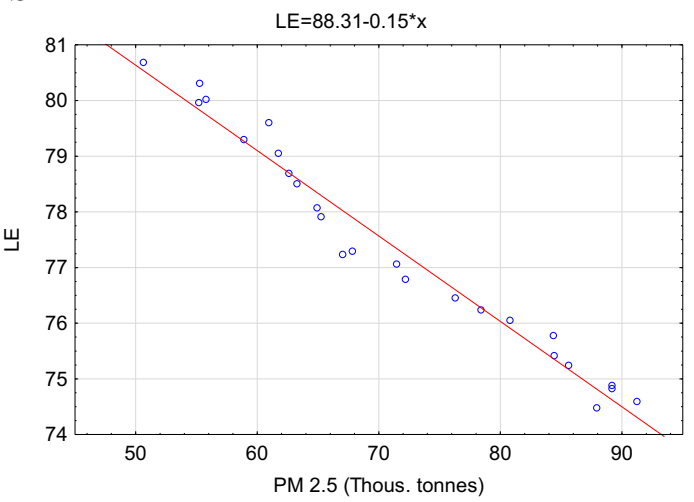

d

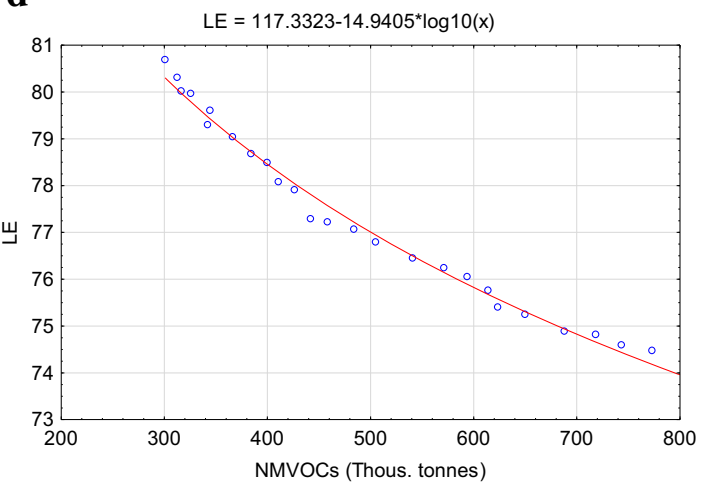

f

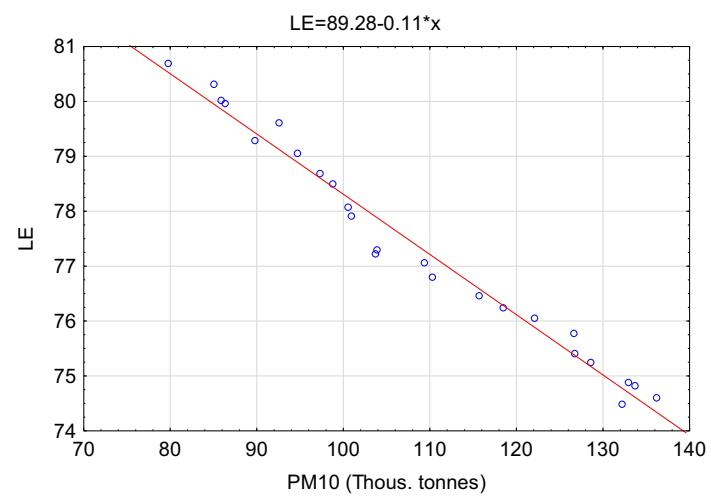


Newton search direction, where $\nabla f(x)$ is the gradient mapping of $f(x)$. In this class of methods $B_{k}$, which is an approximation of the Hessian $\nabla^{2} f\left(x_{k}\right)$, is updated at every iteration with a low-rank matrix. BFGS is a widely used example of a formula which can be applied in order to perform the updates and it is given by

$B_{k+1}=B_{k}-\frac{B_{k} s_{k} s_{k}^{T} B_{k}}{s_{k}^{T} B_{k} s_{k}}+\frac{y_{k} y_{k}^{T}}{y_{k}^{T} s_{k}}$

where $\mathrm{s}_{\mathrm{k}}-\boldsymbol{x}_{\boldsymbol{k}+\mathbf{1}}-\boldsymbol{x}_{\boldsymbol{k}}$ and $\mathrm{y}_{\mathrm{k}}-\nabla f\left(x_{\boldsymbol{k}+1}\right)-\nabla f\left(x_{\boldsymbol{k}}\right)$. BFGS update formula possesses good properties that are very useful for establishing convergence results (Krejić et al. 2009; Kolasa-Więcek 2018).

\section{Materials}

The subject of the analysis included the input (explanatory) variables of the following air pollutants: sulphur oxides $\left(\mathrm{SO}_{\mathrm{x}}\right)$, $\mathrm{NO}_{\mathrm{x}}, \mathrm{CO}, \mathrm{PM} 2.5$ and PM10, polycyclic aromatic hydrocarbons (PAHs) and non-methane volatile organic compounds (NMVOCs). Emission data were retrieved from the European database (Eurostat, European Union emission inventory report 1990-2016). The dependent variable (output) in the form of LE was obtained from OECD databases (OECD). Due to lack of data for the analysed period of 25 years, the modelling was finally performed for only 20 European countries. In some cases (e.g. in case of data for PAHs), the missing data was supplemented with averaged data from two neighbouring years. The modelling was performed for the averaged data of all 20 European countries and, due to the different levels of pollution in individual countries, separately for each of them. The descriptive statistics of the data set for all European countries is presented in Table 1.

\section{Results and discussions}

Our findings suggested that air quality plays an important role in LE of the residents of European countries. An interesting aspect of this research is that it is a simple, direct, and transparent exploration of the association between air pollution and LE. Air pollution control should be reinforced in the future, especially for fine particles that constitute a great influence on LE (Table 4).

The values presented in Table 2 show a summary of the Pearson correlation coefficients between LE and analysed pollutions for European countries. All variables are statistically significant (for $p<0.05$ ). Obtained values of Pearson coefficients indicate a strong relationship between LE and individual pollutants. With an increase in the amount of pollutants, LE decreases.

Table 3 presents the best generated MLP networks for individual countries obtained as a result of modelling. In the first of the analysed cases (20 European countries jointly), a tree-layer MLP network with 7 neurons in the first layer, 11 neurons in the hidden layer, and 1 output layer achieved greatest prediction efficiency. A single neuron at the output of the network reflects the LE. As a result of the tests, the correlation between real and descriptive values expressed in Pearson coefficients was obtained. Received network quality parameters (learning, testing, validation) are very high —over 99\% in all cases. Validation and test prediction errors are parameters that testify to the quality of the network, and their similar values indicate that the network generalizes acquired knowledge well. The quasi-Newton BFGS algorithm, which uses the inverse of the matrix of the second derivatives of the error function counted against successive weights, proved to be the most useful learning algorithm.

The basic measure of network sensitivity is the error quotient obtained on launching the network for a set of variables without one variable and the error obtained with a full set of variables. The bigger the error after rejecting the variable in relation to the original error, the more sensitive the network is to the lack of that variable. If the error quotient is smaller than 1 , then deleting the variable does not affect network sensitivity; it even improves it. The global SA for the inputs indicates that each of the variables obtained the values above 1 , or rounded 1 , which suggests a significant impact of each of them on the output variable.

Table 4 presents the summary of the value of global SA for all countries under study and for studied pollutants.
Table 1 Statistical description of the data

\begin{tabular}{llllll}
\hline Variable & Mean & Standard deviation & Min & Max & Median \\
\hline NMVOCs $^{1}$ & 493.116 & 145.629 & 300.771 & 773.065 & 457.774 \\
NOx & 575.447 & 133.121 & 353.819 & 804.594 & 568.67 \\
PM2.5 & 71.216 & 12.345 & 50.616 & 91.215 & 67.836 \\
PM10 & 108.494 & 17.347 & 79.779 & 136.205 & 103.921 \\
SOx & 456.611 & 300.094 & 126.646 & 1143.401 & 356.932 \\
CO & 1703.372 & 582.502 & 973.104 & 2850.794 & 1523.435 \\
PAHs & 0.216 & 0.135 & 0.073 & 0.518 & 0.151 \\
LE $^{2}$ & 77.380 & 1.924 & 74.485 & 80.69 & 77.23 \\
\hline
\end{tabular}

${ }^{1}$ All air pollutions in thous. tonnes. ${ }^{2}$ In years 
Table 2 Pearson correlation coefficients matrix

\begin{tabular}{lllllllll}
\hline Variable & NMVOCs & $\mathrm{NO}_{\mathrm{x}}$ & $\mathrm{PM} 2.5$ & $\mathrm{PM} 10$ & $\mathrm{SO}_{\mathrm{x}}$ & $\mathrm{CO}$ & $\mathrm{PAHs}$ & $\mathrm{LE}$ \\
\hline NMVOCs & 1.000 & & & & & & & \\
$\mathrm{NO}_{\mathrm{x}}$ & 0.985 & 1.000 & & & & & \\
$\mathrm{PM} 2.5$ & 0.986 & 0.982 & 1.000 & & & & \\
$\mathrm{PM} 10$ & 0.986 & 0.987 & 0.999 & 1.000 & & & \\
$\mathrm{SO}_{\mathrm{x}}$ & 0.983 & 0.955 & 0.950 & 0.949 & 1.000 & & \\
$\mathrm{CO}$ & 0.997 & 0.976 & 0.981 & 0.980 & 0.991 & 1.000 & & \\
$\mathrm{POHs}$ & 0.973 & 0.939 & 0.946 & 0.943 & 0.989 & 0.983 & 1.000 & \\
LE & 0.977 & -0.992 & -0.984 & -0.988 & -0.932 & -0.965 & -0.923 & 1.000 \\
\hline
\end{tabular}

For the summarily analysed 20 countries, PM2.5 is the pollutant which, based on MLP neural network, showed the most significant impact on LE. The dominant emissions in Europe are mainly released by several countries: Germany, France, Poland, Italy, UK and Spain (Fig. 2a). SA of the MLP 7-11-1 network showed the highest sensitivity to changes in PM emissions in relation to LE in the case of large European economies - Germany, Spain, Italy, and Poland (where PM pollutants are located on the second and third positions). The sensitivity of the designed neural network to PM pollution (both PM2.5 and PM10) in these countries is as follows: Germany PM2.5 (3082.86), Spain PM2.5 (18.31), Italy PM10 (463.74) and PM2.5 (273.82), Poland PM10 (1.95) and PM2.5 (1.48). During coal combustion millions of tons of coal fly ash
(CFA) and coal dust were emitted annually to contribute to the formation of PM, and, therefore, underlying risks to LE (Chen et al. 2004; Miller et al. 2007; Munawer 2018).

Out of the 20 countries under study, the SA for 6 countries (MLP 7-10-1, MLP 7-7-1, MLP 7-5-1, MLP 7-8-1, MLP 7-111) showed the greatest sensitivity to $\mathrm{SO}_{\mathrm{x}}$ pollution changes. These are the following countries: Hungary (90.78), Ireland (5.50), Luxembourg (9.55), Poland (33.96), Slovenia (129.99), Sweden (19.65). Coal is a heavily polluting fuel in terms of black carbon (BC), sulphates and other gaseous compounds, especially when incompletely and inefficiently combusted. Numerous studies indicate several diseases resulting from human exposure to $\mathrm{SO}_{\mathrm{x}}$ compounds. For example, inhaling $\mathrm{SO}_{\mathrm{x}}$ pollutants can be a cause of heart attacks as it destabilizes the

Table 3 Summary of active MLP networks for individual countries

\begin{tabular}{|c|c|c|c|c|c|c|c|c|}
\hline Country & Type of network & learn. & $\begin{array}{l}\text { Quality } \\
\text { test. }\end{array}$ & valid. ${ }^{1}$ & learn. & $\begin{array}{l}\text { Error } \\
\text { test. }\end{array}$ & valid. & Algorithm of learning \\
\hline European countries summary & MLP 7-11-1 & 0.998 & 0.999 & 0.999 & 0.004 & 0.001 & 0.005 & BFGS 41 \\
\hline Austria & MLP 7-12-1 & 0.995 & 0.990 & 0.999 & 0.017 & 0.015 & 0.175 & BFGS 10 \\
\hline Belgium & MLP 7-9-1 & 0.996 & 0.993 & 0.999 & 0.008 & 0.012 & 0.098 & BFGS 48 \\
\hline Czechia & MLP 7-4-1 & 0.998 & 0.992 & 0.999 & 0.005 & 0.018 & 0.073 & BFGS 32 \\
\hline Denmark & MLP 7-6-1 & 0.996 & 0.993 & 0.999 & 0.011 & 0.011 & 0.087 & BFGS 29 \\
\hline Estonia & MLP 7-11-1 & 0.992 & 0.994 & 0.998 & 0.076 & 0.046 & 0.031 & BFGS 25 \\
\hline Finland & MLP 7-8-1 & 0.997 & 0.999 & 0.999 & 0.006 & 0.001 & 0.031 & BFGS 33 \\
\hline France & MLP 7-10-1 & 0.992 & 0.999 & 0.999 & 0.025 & 0.015 & 0.088 & BFGS 24 \\
\hline Germany & MLP 7-9-1 & 0.999 & 0.999 & 0.999 & 0.002 & 0.002 & 0.027 & BFGS 43 \\
\hline Hungary & MLP 7-10-1 & 0.994 & 0.998 & 0.999 & 0.022 & 0.013 & 0.022 & BFGS 27 \\
\hline Ireland & MLP 7-7-1 & 0.993 & 0.998 & 0.997 & 0.032 & 0.004 & 0.081 & BFGS 10 \\
\hline Italy & MLP 7-4-1 & 0.996 & 0.999 & 0.999 & 0.011 & 0.010 & 0.048 & BFGS 29 \\
\hline Luxembourg & MLP 7-5-1 & 0.976 & 0.997 & 0.999 & 0.096 & 0.035 & 0.091 & BFGS 37 \\
\hline Netherland & MLP 7-11-1 & 0.998 & 0.999 & 0.999 & 0.002 & 0.004 & 0.001 & BFGS 59 \\
\hline Poland & MLP 7-8-1 & 0.986 & 0.985 & 0.999 & 0.067 & 0.059 & 0.069 & BFGS 12 \\
\hline Portugal & MLP 7-9-1 & 0.995 & 0.999 & 0.999 & 0.023 & 0.012 & 0.017 & BFGS 22 \\
\hline Slovakia & MLP 7-7-1 & 0.993 & 0.996 & 0.999 & 0.015 & 0.013 & 0.045 & BFGS 36 \\
\hline Slovenia & MLP 7-9-1 & 0.996 & 0.999 & 0.998 & 0.022 & 0.011 & 0.018 & BFGS 22 \\
\hline Sweden & MLP 7-11-1 & 0.987 & 0.994 & 0.999 & 0.021 & 0.010 & 0.081 & BFGS 14 \\
\hline UK & MLP 7-7-1 & 0.996 & 0.994 & 0.999 & 0.010 & 0.011 & 0.026 & BFGS 13 \\
\hline
\end{tabular}

${ }^{1}$ Learning, testing, validation 
Table 4 Results of SA

\begin{tabular}{|c|c|c|c|c|c|c|c|}
\hline Country & Variable & & & & & & \\
\hline \multirow{2}{*}{$\begin{array}{l}\text { European } \\
\text { countries }\end{array}$} & PM2.5 & PAHs & $\mathrm{SO}_{\mathrm{x}}$ & NMVOCs & $\mathrm{CO}$ & PM10 & $\mathrm{NO}_{\mathrm{x}}$ \\
\hline & 102.67 & 47.97 & 47.45 & 35.97 & 31.37 & 24.94 & 16.08 \\
\hline \multirow[t]{2}{*}{ Austria } & PM10 & PM2.5 & $\mathrm{CO}$ & $\mathrm{SO}_{\mathrm{x}}$ & $\mathrm{NO}_{\mathrm{x}}$ & PAHs & NMVOCs \\
\hline & 21.38 & 20.98 & 4.955 & 1.65 & 1.11 & 1.03 & 1.00 \\
\hline \multirow[t]{2}{*}{ Belgium } & $\mathrm{CO}$ & NMVOCs & PM10 & $\mathrm{NO}_{\mathrm{x}}$ & PM2.5 & PAHs & $\mathrm{SO}_{\mathrm{x}}$ \\
\hline & 30.89 & 23.02 & 18.58 & 7.81 & 7.18 & 3.58 & 2.99 \\
\hline \multirow[t]{2}{*}{ Czechia } & PM2.5 & PAHs & PM10 & NMVOCs & $\mathrm{NO}_{\mathrm{x}}$ & $\mathrm{CO}$ & $\mathrm{SO}_{\mathrm{x}}$ \\
\hline & 107.88 & 81.39 & 23.94 & 21.85 & 15.55 & 14.97 & 4.71 \\
\hline \multirow[t]{2}{*}{ Denmark } & NMVOCs & NOx & $\mathrm{CO}$ & PAHs & PM10 & PM2.5 & $\mathrm{SO}_{\mathrm{x}}$ \\
\hline & 29.86 & 10.85 & 4.63 & 2.28 & 1.88 & 1.18 & 1.14 \\
\hline \multirow[t]{2}{*}{ Estonia } & NMVOCs & $\mathrm{SO}_{\mathrm{x}}$ & PAHs & $\mathrm{CO}$ & NOx & PM10 & PM2.5 \\
\hline & 59.88 & 40.59 & 35.62 & 7.78 & 7.19 & 7.04 & 3.46 \\
\hline \multirow[t]{2}{*}{ Finland } & $\mathrm{CO}$ & NMVOCs & PAHs & PM10 & PM2.5 & $\mathrm{NO}_{\mathrm{x}}$ & $\mathrm{SO}_{\mathrm{x}}$ \\
\hline & 66.43 & 57.23 & 14.51 & 8.93 & 4.14 & 1.63 & 1.22 \\
\hline \multirow[t]{2}{*}{ France } & NMVOCs & $\mathrm{SO}_{\mathrm{x}}$ & $\mathrm{NO}_{\mathrm{x}}$ & $\mathrm{CO}$ & PAHs & PM2.5 & PM10 \\
\hline & 10.85 & 3.38 & 2.79 & 2.14 & 1.69 & 1.35 & 1.17 \\
\hline \multirow[t]{2}{*}{ Germany } & PM2.5 & $\mathrm{NO}_{\mathrm{x}}$ & PM10 & NMVOCs & $\mathrm{CO}$ & $\mathrm{SO}_{\mathrm{x}}$ & PAHs \\
\hline & 3082.86 & 286.67 & 120.98 & 45.65 & 15.78 & 5.08 & 4.04 \\
\hline \multirow[t]{2}{*}{ Hungary } & $\mathrm{SO}_{\mathrm{x}}$ & PM10 & $\mathrm{CO}$ & PM2.5 & $\mathrm{NO}_{\mathrm{x}}$ & NMVOCs & PAHs \\
\hline & 90.78 & 36.09 & 14.37 & 8.25 & 4.26 & 3.00 & 1.63 \\
\hline \multirow[t]{2}{*}{ Ireland } & $\mathrm{SO}_{\mathrm{x}}$ & $\mathrm{NO}_{\mathrm{x}}$ & $\mathrm{CO}$ & PAHs & NMVOCs & PM10 & PM2.5 \\
\hline & 5.50 & 1.75 & 1.72 & 1.21 & 1.20 & 1.00 & 0.98 \\
\hline \multirow[t]{2}{*}{ Italy } & PM10 & PM2.5 & $\mathrm{NO}_{\mathrm{x}}$ & $\mathrm{CO}$ & $\mathrm{SO}_{\mathrm{x}}$ & PAHs & NMVOCs \\
\hline & 463.74 & 273.82 & 35.29 & 13.28 & 8.27 & 2.42 & 2.30 \\
\hline \multirow[t]{2}{*}{ Luxembourg } & $\mathrm{SO}_{\mathrm{x}}$ & NMVOCs & $\mathrm{CO}$ & PM2.5 & PM10 & PAHs & $\mathrm{NO}_{\mathrm{x}}$ \\
\hline & 9.55 & 7.61 & 6.37 & 5.81 & 5.52 & 2.72 & 1.46 \\
\hline \multirow[t]{2}{*}{ Netherland } & $\mathrm{NO}_{\mathrm{x}}$ & PM2.5 & PM10 & NMVOCs & $\mathrm{CO}$ & PAHs & $\mathrm{SO}_{\mathrm{x}}$ \\
\hline & 1117.15 & 473.28 & 356.10 & 112.41 & 53.21 & 28.18 & 16.68 \\
\hline \multirow[t]{2}{*}{ Poland } & $\mathrm{SO}_{\mathrm{x}}$ & PM10 & PM2.5 & $\mathrm{NO}_{\mathrm{x}}$ & $\mathrm{CO}$ & NMVOCs & PAHs \\
\hline & 33.96 & 1.95 & 1.48 & 1.23 & 1.13 & 1.10 & 0.99 \\
\hline \multirow[t]{2}{*}{ Portugal } & $\mathrm{NO}_{\mathrm{x}}$ & $\mathrm{SO}_{\mathrm{x}}$ & PAHs & $\mathrm{CO}$ & PM10 & PM2.5 & NMVOCs \\
\hline & 47.57 & 43.35 & 41.43 & 15.61 & 7.23 & 4.93 & 1.30 \\
\hline \multirow[t]{2}{*}{ Slovenia } & $\mathrm{SO}_{\mathrm{x}}$ & NMVOCs & $\mathrm{CO}$ & PAHs & $\mathrm{NO}_{\mathrm{x}}$ & PM2.5 & PM10 \\
\hline & 129.99 & 44.21 & 18.00 & 11.68 & 8.16 & 6.21 & 1.58 \\
\hline \multirow[t]{2}{*}{ Spain } & PM2.5 & PAHs & PM10 & NMVOCs & $\mathrm{SO}_{\mathrm{x}}$ & $\mathrm{CO}$ & $\mathrm{NO}_{\mathrm{x}}$ \\
\hline & 18.31 & 12.69 & 2.46 & 2.33 & 1.97 & 1.67 & 1.45 \\
\hline \multirow[t]{2}{*}{ Sweden } & $\mathrm{SO}_{\mathrm{x}}$ & $\mathrm{CO}$ & PM10 & NMVOCs & $\mathrm{NO}_{\mathrm{x}}$ & PM2.5 & PAHs \\
\hline & 19.65 & 8.52 & 4.26 & 2.14 & 1.99 & 1.85 & 1.72 \\
\hline \multirow[t]{2}{*}{ UK } & $\mathrm{CO}$ & $\mathrm{NO}_{\mathrm{x}}$ & PM2.5 & $\mathrm{SO}_{\mathrm{x}}$ & NMVOCs & PM10 & PAHs \\
\hline & 163.69 & 53.21 & 28.17 & 14.82 & 9.27 & 5.02 & 1.03 \\
\hline
\end{tabular}

rhythm of heart beats (Peters et al. 1999). Populations inhabiting areas in the proximity of power plants frequently suffered from suffocation, wheezing and coughing, and their lung function was reduced due to high exposure to $\mathrm{SO}_{2}$ (Bascom 1996). Among the effects of $\mathrm{SO}_{2}$ pollution are also bronchial reactions, premature death and numerous diseases, such as lung and colon cancers (Hussain et al. 2016; Pourgholami et al. 2005).
Sensitivity of the neural network to CO pollution was obtained in four European countries: Belgium (30.89), Finland (10.85), Portugal (47.57) and UK (163.69). During coal combustion, as a result of oxidation, $\mathrm{CO}_{2}$ and $\mathrm{CO}$ gases are emitted. They lead to harmful environmental effects in the form of global warming and GHG emissions and are also correlated directly and indirectly with many health problems, including 


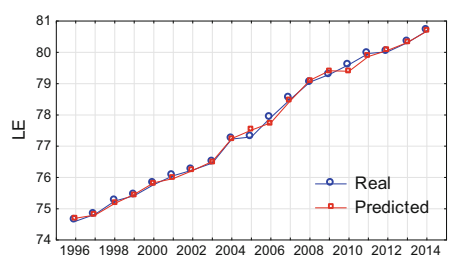

(EU)

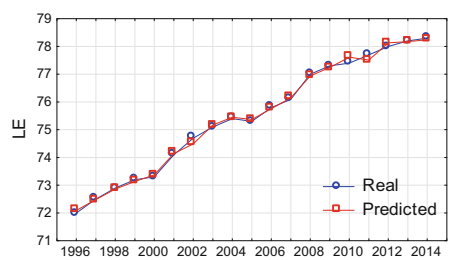

(Czech Republik )

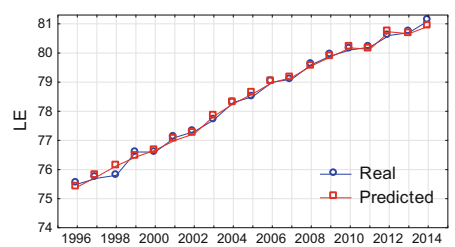

(Finland)

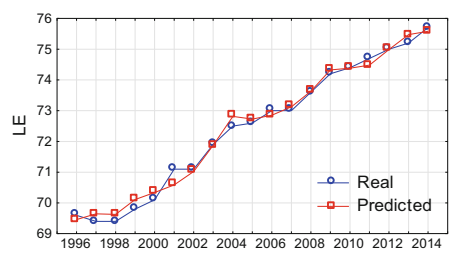

(Hungary)

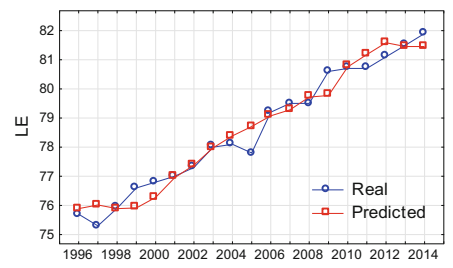

(Luxemburg)

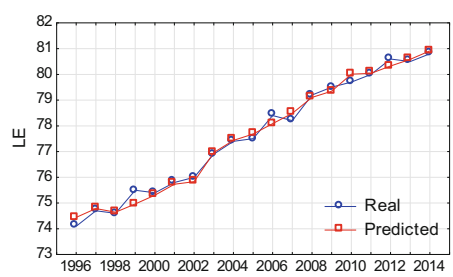

(Portugal)

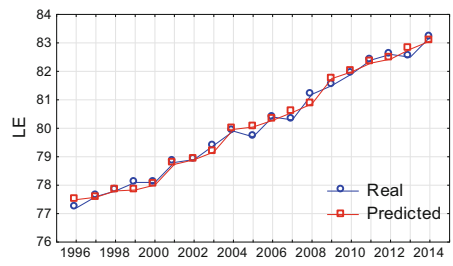

(Spain)

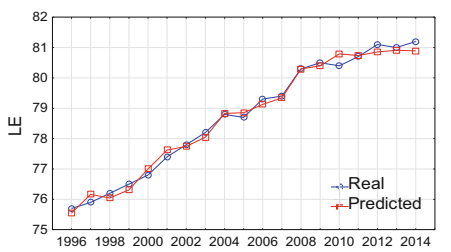

(Austria)

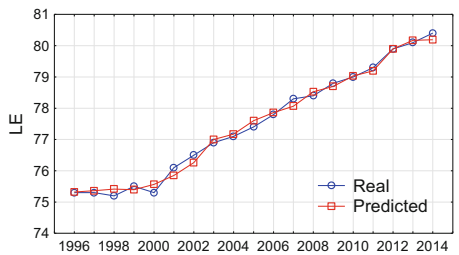

(Denmark)

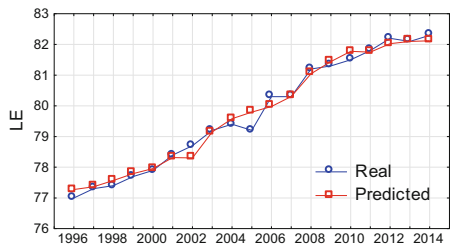

(France)

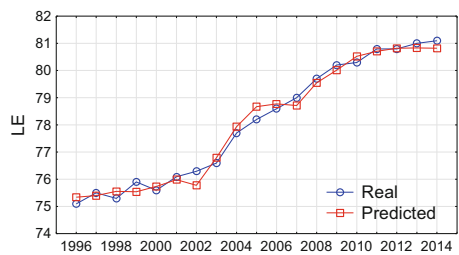

(Ireland)

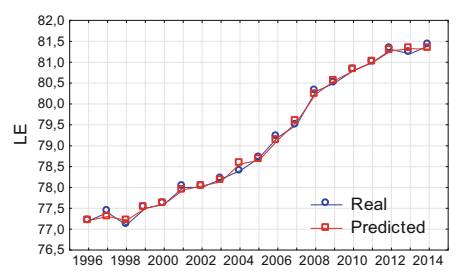

(Netherland)

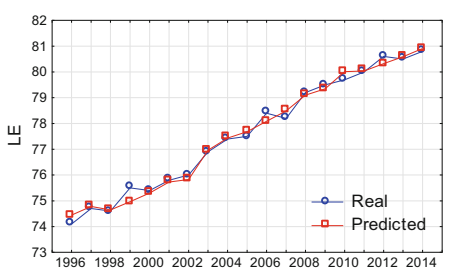

(Slovakia)

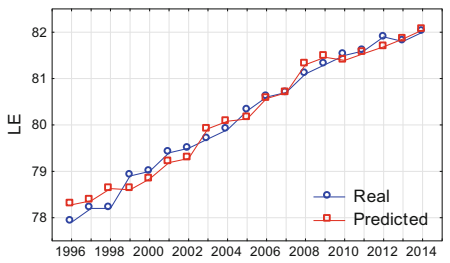

(Sweden)

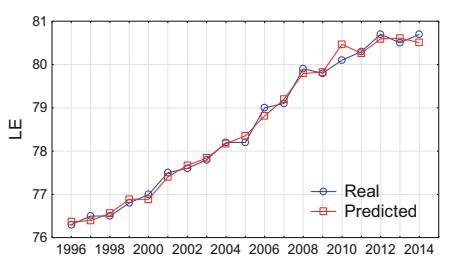

(Belgium)

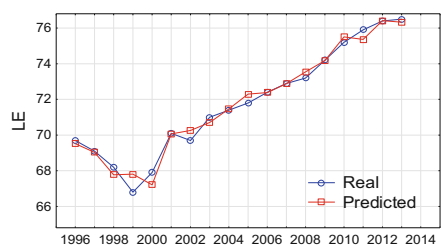

(Estonia)

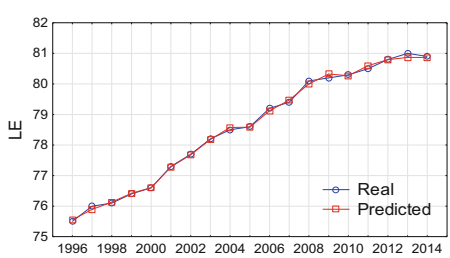

(Germany)

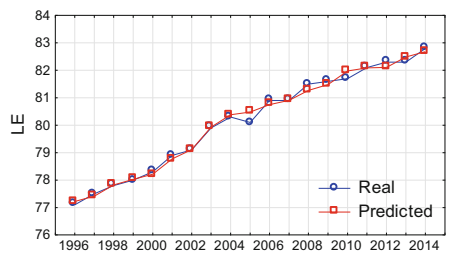

(Italy)

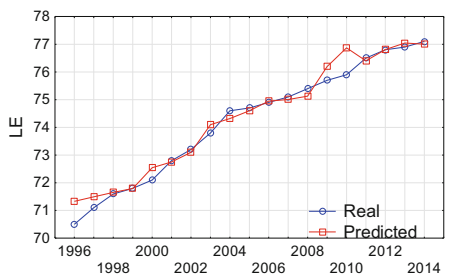

(Poland)

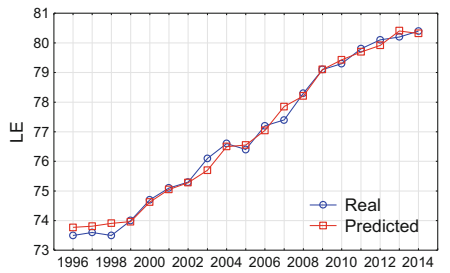

(Slovenia)

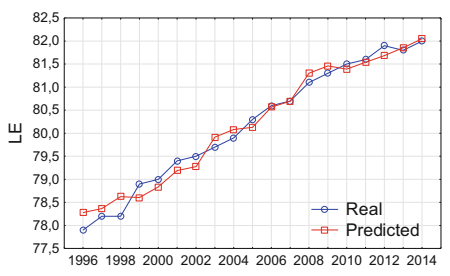

(UK)

Fig. 6 Observed and modelled value of LE 
malaria, cardiovascular diseases and asthma (Munawer 2018). At a cellular level, the $\mathrm{CO}$ combines with blood haemoglobin reducing its efficiency and lowering its capacity to transform $\mathrm{O}_{2}$ (Badman and Jaffé 1996).

In Denmark (29.86), Estonia (59.88) and France (10.85), the highest sensitivity of the neural network to changes in NMVOC pollution was obtained. NMVOCs have been shown to be responsible for several health problems. Among them respiratory and cardiovascular system diseases can be noted, which are related to an increased concentration of tropospheric ozone and secondary organic aerosols due to NMVOC pollution (Laurent and Hauschild 2014). Some toxic NMVOCs, e.g. benzene and formaldehyde, can have a more direct impact on human health. They can be a direct cause of acute and chronic diseases and be carcinogenic or mutagenic (Weichenthal et al. 2012).

The data obtained as a result of modelling were compared with the actual data. Forecasted courses of changes in the variable under study coincide with the actual data, which confirms that the proposed models generalize acquired knowledge well (Fig. 6).

The models (sensitivity of constructed neural networks to pollutants) proved to be particularly important (depending on the country) in the case of changes in the value of PM (PM2.5 and PM10), $\mathrm{SO}_{\mathrm{x}}$ and NMVOC. The methods under study allow for quantification of the deterministic relationship between emissions and LE, including the consequences of past and upcoming scenarios, and the determination of the effectiveness of air pollution management strategies. This makes the models indispensable in several research applications. The SA of inputs has proven to be a useful technique for understanding the mechanism of the modelled function, giving more insight into the internal mechanism of the ANN model. It also helps to understand the relative contribution of input parameters that can be used to eliminate irrelevant inputs to make the model more robust. The obtained values of Pearson coefficients indicate a high negative relationship between LE and individual pollutants, which means that with an increase of the emissions, LE decreases. The proposed approach can be used to illustrate how the neural network modelling technique can be used to identify the key air pollution variables required to adequately capture the variability in LE for a specific scenario. The presented models can be used not only for LE forecasting but also for simulating various scenarios by changing the values of the input variables.

\section{Conclusions}

The study suggests an association between long-term air pollution exposure and the reduction of LE. The air pollutants PM10, PM2.5, $\mathrm{NO}_{\mathrm{x}}, \mathrm{NMVOC}, \mathrm{SO}_{\mathrm{x}}$, PAHs and $\mathrm{CO}$ were identified as correlated with LE. The most frequent association was found for fine particle.

Constructed models, thanks to the network's ability to generalize data, can be used in the prediction of the LE value, based on the analysed air pollutants. Proposed models can be used to simulate LE scenarios and can be used by regulatory authorities to support policy creation and implementation process, and for the development of strategies for improving air quality at regional and national levels. The results of the study can also support the development and effective implementation of long-term policies that reduce the risk of impact of individual air pollutants on human health and life.

Open Access This article is distributed under the terms of the Creative Commons Attribution 4.0 International License (http:// creativecommons.org/licenses/by/4.0/), which permits unrestricted use, distribution, and reproduction in any medium, provided you give appropriate credit to the original author(s) and the source, provide a link to the Creative Commons license, and indicate if changes were made.

\section{References}

Abdul-Wahab SA, Bakheit CS, Al-Alawi SM (2005) Principal component and multiple regression analysis in modelling of ground-level ozone and factors affecting its concentrations. Environ Modell Softw 20(10):1263-1271. https://doi.org/10.1016/j.envsoft.2004. 09.001

Aboubacar B, Deyi X, Razak MYA, Leyla BH (2018) The Effect of PM2.5 from household combustion on life expectancy in SubSaharan Africa. Int J Environ Res Public Health 15(4):748. https:// doi.org/10.3390/ijerph15040748

Alessandrini ER, Stafoggia M, Faustini A (2016) Association between short-term exposure to PM2.5and PM10 and mortality in susceptible subgroups: a multisite case-crossover analysis of individual effect modifiers. Am J Epidemiol 184(10):744-754. https://doi.org/10. 1093/aje/kww078

Ashraf A, Butt A, Khalid I, Alam RU, Ahmad SR (2019) Smog analysis and its effect on reported ocular surface diseases: a case study of 2016 smog event of Lahore. Atmos Environ 198:257-264. https:// doi.org/https://doi.org/10.1016/j.atmosenv.2018.10.029

Badman DG, Jaffé ER (1996) Blood and air pollution; state of knowledge and research needs. Otolaryn head neck 114(2):205-208. https://doi. org/10.1016/S0194-59989670166-3

Broyden CG (1965) A class of methods for solving nonlinear simultaneous equations. Math Comput 19:577-559

Cacciotolo M, Wang X, Driscoll I et al (2017) Particulate air pollutants, APOE alleles and their contribution to cognitive impairment in older women and in amyloidogenesis in experimental model. Transl Psychiatr 7(1):e1022. https://doi.org/10.1038/tp.2016.280

Chen Y, Shah N, Huggins FE (2004) Investigation of primary fine particulate matter from coal combustion by computer-controlled scanning electron microscopy. Fuel Process Technol 85(6):743-761. https://doi.org/10.1016/j.fuproc.2003.11.017

de Keijzer C, Agis D, Ambrós A, Arévalo G, Baldasano JM, Bande S, Barrera-Gómez J, Benach J, Cirach M, Dadvand P, Ghigo S, Martinez-Solanas È, Nieuwenhuijsen M, Cadum E, Basagaña X (2017) The association of air pollution and greenness with mortality and life expectancy in Spain: a small-area study. Environ Int 99: 170-176. https://doi.org/10.1016/j.envint.2016.11.009 
Dziubanek G, Spychała A, Marchwińska-Wyrwał E, Rusi M, Hajok I, Ćwielag-Drabek M, Piekut A (2017) Long-term exposure to urban air pollution and the relationship with life expectancy in cohort of 3.5 million people in Silesia. Sci Total Environ. 580:1-8. https://doi. org/10.1016/j.scitotenv.2016.11.217

Ebenstein A, Fan M, Greenstone M, He G, Zhouh M (2017) New evidence on the impact of sustained exposure to air pollution on life expectancy from China's Huai River Policy. Proc Natl Acad Sci USA 114(39):10384-10389. https://doi.org/10.1073/pnas. 1616784114

Etchie TO, Etchie AT, Adewuyi GO, Pillarisetti A, Arora NK (2018) The gains in life expectancy by ambient PM2.5 pollution reductions in localities in Nigeria. Environ Pollut 236:146-157. https://oi.org/10. 1016/j.envpol.2018.01.034

European Economic Area, EEA https://www.eea.europa.eu/data-andmaps/indicators/exceedance-of-air-quality-limit-3/assessment-4, (accessed on 12.12.2018)

European Environment Agency, Air quality in Europe - 2016 report, EEA Report No 28/2016. https://doi.org/10.2800/80982 (accessed on 21.12.2018)

European Union emission inventory report 1990-2016 under the UNECE Convention on Long-range Transboundary Air Pollution (LRTAP). EEA Report No 6/2018 (accessed on 5.12.2018)

Eurostat. https://ec.europa.eu/eurostat/data/statistics-a-z/def (accessed on 1.11.2018)

Fann N, Kim S-Y, Olives C, Sheppard L (2017) Estimated changes in life expectancy and adult mortality resulting from declining PM2.5 exposures in the contiguous United States: 1980-2010. Environ Health Perspect 125(9):097003. https://doi.org/10.1289/EHP507

Fann N, Coffman E, Hajat A, Kim S-Y (2019) Change in fine particlerelated premature deaths among US population subgroups between 1980 and 2010. Air Qual Atmos Health 12:1-10. https://doi.org/10. 1007/s11869-019-00686-9

Guerreiro CBB, Foltescu V, Leeuw F (2014) Air quality status and trends in Europe. Atmos Environ 98:376-384. https://doi.org/10.1016/j. atmosenv.2014.09.017

Hill TD, Jorgenson AK, Ore P, Balistreri KS, Clark B (2019) Air quality and life expectancy in the United States: An analysis of the moderating effect of income inequality. In: Air quality and life expectancy in the United States: an analysis of the moderating effect of income inequality. SSM - Population Health. 7, Article 100346. https://doi. org/10.1016/j.ssmph.2018.100346

Hussain MRM, Din N, Hassan M, Razaq A, Iqbal Z (2016) Physiological significance of Fuc and sialic acid containing glycans in the body. Arab J Chem 9(1):S9-S20. https://doi.org/10.1016/j.arabjc.2011.06. 028

Jonker MF, van Lenthe FJ, Donkers B, Mackenbach JP, Burdorf A (2014) The effect of urban green on small-area (healthy) life expectancy. J Epidemiol Community Health. 2014 Oct; 68(10):999-1002. https:// doi.org/10.1136/jech-2014-203847. 999.

Kolasa-Więcek A (2018) Neural modeling of greenhouse gas emission from agricultural sector in European Union member countries. Water Air Soil Poll 229(6):205. https://doi.org/10.1007/s11270018-3861-7

Krejić N, Lužanin Z, Stojkovska I (2009) Gauss-Newtonbased BFGS method with filter for unconstrained minimization. App Math Comput 211(2):354-362. https://doi.org/10.1016/j.amc.2009.01. 041

Laurent A, Hauschild MZ (2014) Impacts of NMVOC emissions on human health in European countries for 2000-2010: use of sectorspecific substance profiles. Atmos Environ 85:247-255. https://doi. org/10.1016/j.atmosenv.2013.11.060

Li Y, Henze DK, Darby KJPL (2016) The influence of air quality model resolution on health impact assessment for fine particulate matter and its components. Air Qual Atmos Health 9(1):51-68. https:// doi.org/10.1007/s11869-015-0321-Z

Liu H, Duan Z, Chen C (2019) A hybrid framework for forecasting PM2.5 concentrations using multi-step deterministic and probabilistic strategy. Air Qual Atmos Health 12:1-11. https://doi.org/10. 1007/s11869-019-00695-8

Mehdipour V, Stevenson DS, Memarianfard M, Sihag P (2018) Comparing different methods for statistical modeling of particulate matter in Tehran, Iran. Air Qual Atmos Health 11(10):1155-1165. https://doi.org/10.1007/s11869-018-0615-z

Miller KA, Siscovick DS, Sheppard L, Shepherd K, Sullivan JH, Anderson GL, Kaufman JD (2007) Long-term exposure to air pollution and incidence of cardiovascular events in women. New Eng J Med 356(5):447-458. https://doi.org/10.1056/NEJMoa054409

Munawer ME (2018) Human health and environmental impacts of coal combustion and post-combustion wastes. J Sustain Min 17(2):8796. https://doi.org/10.1016/j.jsm.2017.12.007

OECD, https://data.oecd.org/healthstat/life-expectancy-at-birth.htm (accessed on 28.11.2018)

Park YM, Kwan MP (2017) Individual exposure estimates may be erroneous when spatiotemporal variability of air pollution and human mobility are ignored. Health Place 43:85-94. https://doi.org/10. 1016/j.healthplace.2016.10.002

Peters A, Perz S, Döring A (1999) Increases in heart rate during an air pollution episode. Am J Epidemiol 150(10):1094-1098. https://doi. org/10.1093/oxfordjournals.aje.a009934

Pope CA III, Ezzati M, Dockery DW (2009) Fine-particulate air pollution and life expectancy in the United States. New England J Med 360(4):376-386. https://doi.org/10.1056/NEJMsa0805646

Pope CA III, Ezzati M, Dockery DW (2015) Tradeoffs between income, air pollution and life expectancy: brief report on the US experience, 1980-2000. Environ Res 142:591-593. https://doi.org/10.1016/j. envres.2015.08.014

Pourgholami MH, Akhter J, Wang L, Lu Y, Morris DL (2005) Antitumor activity of albendazole against the human colorectal cancer cell line HT-29: in vitro and in a xenograft model of peritoneal carcinomatosis. Cancer Chemother Pharmacol 55(5):425-432. https://doi.org/ 10.1007/s00280-004-0927-6

Samoli E, Stafoggia M, Rodopoulou S, Ostro B, Declercq C, Alessandrini E, Díaz J, Karanasiou A, Kelessis AG, le Tertre A, Pandolfi P, Randi G, Scarinzi C, Zauli-Sajani S, Katsouyanni K, Forastiere F, the MED-PARTICLES Study group. (2013) Associations between fine and coarse particles and mortality in Mediterranean cities: results from the MED-PARTICLES project. Environ Health Perspect 121:932-938. https://doi.org/10.1289/ ehp. 1206124

Wang C, Zhou X, Chen R, Duan X, Kuang X, Kan H (2013) Estimation of the effects of ambient air pollution on life expectancy of urban residents in China. Atmos Environ 80:347-351. https://doi.org/10. 1016/j.atmosenv.2013.08.018

Weichenthal S, Kulka R, Bélisle P, Joseph L, Dubeau A, Martin C, Wang D, Dales R (2012) Personal exposure to specific volatile organic compounds and acute changes in lung function and heart rate variability among urban cyclists. Environ Res 118:118-123. https://doi. org/10.1016/j.envres.2012.06.005

World Health Organization, Review of evidence on health aspects of air pollution - REVIHAAP Project Technical Report, WHO Regional Office for Europe $2013 \mathrm{http}: / / \mathrm{www}$. euro.who.int/ data/assets/pdf file/0004/193108/REVIHAAP-Final-technical-report-final-version. pdf?ua $=1$ (accessed on 15.10.2018)

Publisher's note Springer Nature remains neutral with regard to jurisdictional claims in published maps and institutional affiliations. 